\title{
The Impact of Customer Contact on Collective Human Energy in Firms
}

Group \& Organization Management $1-38$

(C) The Author(s) 2018

Reprints and permissions: sagepub.com/journalsPermissions.nav DOI: $10.1177 / 1059601118783120$ journals.sagepub.com/home/gom

(S)AGE

\section{Petra Kipfelsberger', Heike Bruch', and Dennis Herhausen'}

\begin{abstract}
This article investigates how and when a firm's level of customer contact influences the collective organizational energy. For this purpose, we bridge the literature on collective human energy at work with the job impact framework and organizational sensemaking processes and argue that a firm's level of customer contact is positively linked to the collective organizational energy because a high level of customer contact might make the experience of prosocial impact across the firm more likely. However, as prior research at the individual level has indicated that customers could also deplete employees' energy, we introduce transformational leadership climate as a novel contingency factor for this linkage at the organizational level. We propose that a medium to high transformational leadership climate is necessary to derive positive meaning from customer contact, whereas firms with a low transformational leadership climate do not get energized by customer contact. We tested the proposed moderated mediation model with multilevel modeling and a multisource data set comprising 9,094 employees and 75 key informants in 75 firms. The results support our hypotheses and offer important theoretical contributions for research on collective human energy in organizations and its interplay with customers.
\end{abstract}

\section{Keywords}

human energy in organizations, customer contact, multilevel modeling, prosocial impact, transformational leadership climate

\footnotetext{
'University of St. Gallen, Switzerland
}

\section{Corresponding Author:}

Petra Kipfelsberger, Institute for Leadership and Human Resource Management, University of St. Gallen, Dufourstrasse 40a, CH-9000 St. Gallen, Switzerland.

Email: petra.kipfelsberger@unisg.ch 
In times of ongoing changes and increasing demands, firms need, more than ever, an energized and productive workforce to prosper and not just to survive. In these circumstances, research on human energy at work has gained momentum (e.g., Atwater \& Carmeli, 2009; Christian, Eisenkraft, \& Kapadia, 2014; Fritz, Lam, \& Spreitzer, 2011; Quinn, Spreitzer, \& Lam, 2012). As the overall collective level of human energy might contribute to a more holistic understanding of energy in organizations than the energy level of individual organizational members (Bruch \& Ghoshal, 2003), focusing on productive organizational energy holds great potential. Productive organizational energy refers to the force with which an organization functions and encompasses an organization's emotional, cognitive, and physical states (Cole, Bruch, \& Vogel, 2012). Along this line, research has provided evidence that companies with high collective organizational energy are superior in terms of effectiveness (Cole et al., 2012) and employees' well-being (Raes, Bruch, \& De Jong, 2013). Hence, it is crucial for organizations to learn more about the factors, which influence productive organizational energy.

So far, research has shown that factors such as management behavior or organizational structure determine productive organizational energy (Raes et al., 2013; Walter \& Bruch, 2010). However, we have very little knowledge about the potential impact of the social context of one's work, such as the contact to customers, on collective human energy in organizations. In particular, we do not know whether how and when a firm's overall level of customer contact influences the collective human energy in organizations. On one hand, a firm's level of customer contact may decrease the productive organizational energy due to the direct exposure to increasing customer demands and hostility (e.g., Rupp \& Spencer, 2006). On the contrary, a firm's level of customer contact may increase the productive organizational energy due to a more intense and vivid experience of the prosocial impact of the firm by doing good for others, that is, customers (e.g., Grant, 2007).

Extant research on the influences of customer contact on employees at the individual level has yielded contradictory findings (for an overview, see Grandey \& Diamond, 2010). Researchers in the field of job design and especially relational job design consider customer contact as a source of motivation and energy (e.g., Grant, 2007), whereas researchers in the field of emotional labor consider customer contact as a potential source of stress draining employees' energy (e.g., Grandey, 2000). One possible explanation for these opposing perspectives could lie in the different conceptualization of the customer-related construct. Whereas the job impact framework refers to internal and external beneficiaries and, hence, mostly respectful customer 
contact (Grant, 2007; Grant et al., 2007), researchers in the field of emotional labor usually focus on negative experiences due to customer contact, such as customer verbal abuse or mistreatment of employees (Grandey, Kern, \& Frone, 2007; M. Wang, Liao, Zhan, \& Shi, 2011). Consequently, a neutral conceptualization of customer contact as developed by Grant (2008) might be helpful to investigate the overall influence of external customers on the collective energy in organizations.

We propose that firms with a high level of customer contact show a higher level of productive organizational energy and, consequently, are more likely to achieve their goals. A high level of firm's customer contact might trigger employees' experience of making a difference through their work across the organization due to interpersonal sensemaking processes so that collective human energy is activated. In addition, as a high level of firm's customer contact might also include unpleasant and strenuous interactions with customers, which might make it more difficult to distill the firm's prosocial impact, we expect that an organization's transformational leadership climate is an important contingency factor that shapes the influence of a firm's level of customer contact on its productive organizational energy. A transformational leadership climate might thereby help to direct employees' attention to the positive contribution of their work during and after customer interactions regardless of the exact nature of the customer contact.

This research advances the literatures on human energy in organizations and relational job design. First, we introduce customer contact as a novel factor at the organizational level that activates collective human energy in organizations through prosocial impact, which, in turn, improves firm goal achievement. Second, we identify a transformational leadership climate as a contingency of the energizing effects of customer contact, suggesting that only organizations with a high level of transformational leadership climate benefit from contact with customers. Third, while focusing on customers as external beneficiaries, we offer a theoretical and empirical elaboration and extension of the core elements of the job impact framework to the firm impact framework at the organizational level of analysis while incorporating recent research on collective prosocial motivation based on shared helping norms (J. Hu \& Liden, 2014). In doing so, we move job design research beyond the individual level of analysis to a collective level of examination, which researchers have called for (Humphrey, Nahrgang, \& Morgeson, 2007; Oldham \& Hackman, 2010). Together, these advances extend contemporary conversations of how to achieve and maintain a collectively energetic and engaged workforce (e.g., Barrick, Thurgood, Smith, $\&$ Courtright, 2015). 


\section{Theoretical Background and Development of Hypotheses}

\section{Productive Organizational Energy as a Collective Construct}

Productive organizational energy is defined as the shared experience and demonstration of positive affect, cognitive arousal, and agentic behavior among employees in their joint pursuit of organizationally salient objectives (Cole et al., 2012; Walter \& Bruch, 2010). As such, productive organizational energy is characterized by the following two aspects: comprising multiple dimensions and emerging as a relatively stable state at the collective level (Bruch \& Ghoshal, 2003; Cole et al., 2012).

First, to capture the complexity of collective phenomena, scholars have emphasized that dealing with multiple attributes simultaneously is crucial and each dimension needs to be clearly described (McGrath, Arrow, \& Berdahl, 2000; P. M. Podsakoff, MacKenzie, \& Podsakoff, 2016). Productive organizational energy consists of an affective, a cognitive, and a behavioral dimension. Affective energy reflects the degree of shared enthusiasm and strong positive feelings relating to work issues such as tasks, goals, or job challenges (Cole et al., 2012; Quinn \& Dutton, 2005). ${ }^{1}$ Cognitive energy reflects the shared intellectual processes that propel members to persist thinking productively and solution-oriented while being able to focus their attention and shut out distractions (Cole et al., 2012; Lykken, 2005). ${ }^{2}$ Behavioral energy reflects members' joint efforts to achieve the shared goals of an organization and the degree of their pace, intensity, and volume invested for benefiting the organization (Cole et al., 2012; Spreitzer \& Sonenshein, 2004; Spreitzer, Sutcliffe, Dutton, Sonenshein, \& Grant, 2005). Research has shown that these three dimensions of productive organizational energy are conceptually and empirically distinct, and that they conjointly reflect the construct of productive organizational energy (Cole et al., 2012; Walter \& Bruch, 2010). ${ }^{3}$

Second, productive organizational energy reflects the affective, cognitive, and behavioral energy of organizations as a whole. Therewith, productive organizational energy is a collective construct that is functional equivalent to individual-level energy but differs in its structure from it (Cole et al., 2012). Whereas individual-level energy manifests at the intraindividual level via biological and psychological processes, organizational-level energy emerges at the organizational level via mutual dependence and interindividual interaction (Bruch \& Vogel, 2011; Cole et al., 2012). Affect, cognition, and behavior of individual employees represent the "raw material of emergence" (Kozlowski \& Klein, 2000, p. 55), which is transformed and amplified through interaction between employees. In the course of these interactions, 
mechanisms such as emotional contagion processes (Barsade, 2002), organizational sensemaking (Maitlis, 2005), as well as behavioral integration (Bandura, 2001) contribute to the emergence of productive organizational energy on the organizational level. Due to its emergent state, productive organizational energy is relatively stable over time although it varies as a function of its context, inputs, and outcomes (Bruch \& Vogel, 2011; Cole et al., 2012). Evoked by collective alignment and amplification processes, productive organizational energy is more than the sum of individual-level energy and has the potential to exert a much stronger positive force (Bruch \& Ghoshal, 2003; Cole et al., 2012; Rousseau, 1985). Moreover, multilevel theorists have repeatedly recommended using collective-level constructs when investigating collective-level outcomes such as firm goal achievement (Kozlowski \& Klein, 2000; Morgeson \& Hofmann, 1999).

\section{Customer Contact at the Organizational Level}

In line with the definition of beneficiary contact, customer contact is defined as the degree to which employees have the opportunity to meet, communicate, and interact with customers (Grant, 2007, 2008). As customer contact, therewith, is a structural component of one's job characteristic, the overall level of customer contact within an organization represents the extent to which an organization's job profiles include contact with customers on average. Drawing from the open systems perspective (Katz \& Kahn, 1978), recent research regarding the effects of an organization's customer-centric activities on the affective climate within the organization shows that customer-centric activity is an organizational characteristic (Knight, Menges, \& Bruch, 2017). By going beyond the occupational level, these researchers illustrated that individuals across the organization and across jobs are affected by the organizational level of customer-centric activities, although there might be jobrelated and subunit differences within the organization with respect to the degree of customer centricity. While Knight and colleagues differentiated and compared customer-centric, that is, service and retail, with non-customer-centric industries, such as manufacturing, we take a more fine-grained perspective and consider the aggregate level of contact to customers among employees across the organization. ${ }^{4}$ This more accurate conceptualization of customer contact allows us to develop and test a more specific model at the collective organizational level while it moves job design research from the individual level to the collective level.

Customer contact can evoke different consequences for employees in terms of emotions, cognitions, and behaviors (e.g., Grandey \& Diamond, 2010). Although the empirical research on the job impact framework mainly 
considers respectful contact to beneficiaries as the trigger for perceiving one's prosocial impact (Bellé, 2014; Grant, 2012; Grant et al., 2007), Grant (2007) also elaborated within his conceptual work on the idea that even adverse conditions such as unpleasant contact to beneficiaries might help employees to see that their work matters for others. As contact to customers provide access to different types of feedback, Grant (2007) explains that "[b]oth positive and negative feedback convey information to employees that their work has the potential to affect beneficiaries" (p. 400). Recent research suggests that some personal interactions, that could be depleting at firsthand, provide restorative elements for employees, in particular, if employees are able to sense that their work matters, that is, has a prosocial impact in the long-term (Lilius, 2012; Molinsky \& Margolis, 2005). Accordingly, in order not to mix up the employee-related consequences with the determinants, we follow the conceptualization of Grant (2008) and consider depth, breadth, and frequency of customer contact in a descriptive manner at the aggregate level.

In what follows, we will build upon the job impact framework and interpersonal as well as organizational sensemaking processes and elaborate on the indirect and contingent relationship between customer contact and productive organizational energy at the organizational level. Figure 1 provides an overview about the proposed hypotheses, which will be derived in detail in the following.

\section{Customer Contact and Prosocial Impact}

We propose in the following section that a high level of customer contact within an organization will be positively related to the overall degree of perceived prosocial impact among employees. A central notion of the job impact framework developed by Grant (2007) is that connecting and interacting with other people at work, for example, customers, activates employees' prosocial motivation, that is, their desire to have a positive impact on other people. According to this theory, jobs should be designed in such way that they entail many relational and prosocial features. We transfer and expand this framework from the job level to the firm level based on the following reasons: First, organizational members' jobs are interdependent in a firm and their experiences and interpretations of these influence each other through interpersonal sensemaking processes (Wrzesniewski, Dutton, \& Debebe, 2003). Second, not only organizational members want to have a positive impact on other people through their work but also firms as an organizational entity strive for purpose and prosocial impact (Hollensbe, Wookey, Hickey, \& George, 2014). As "satisfy[ing] the customer is the mission and purpose of 


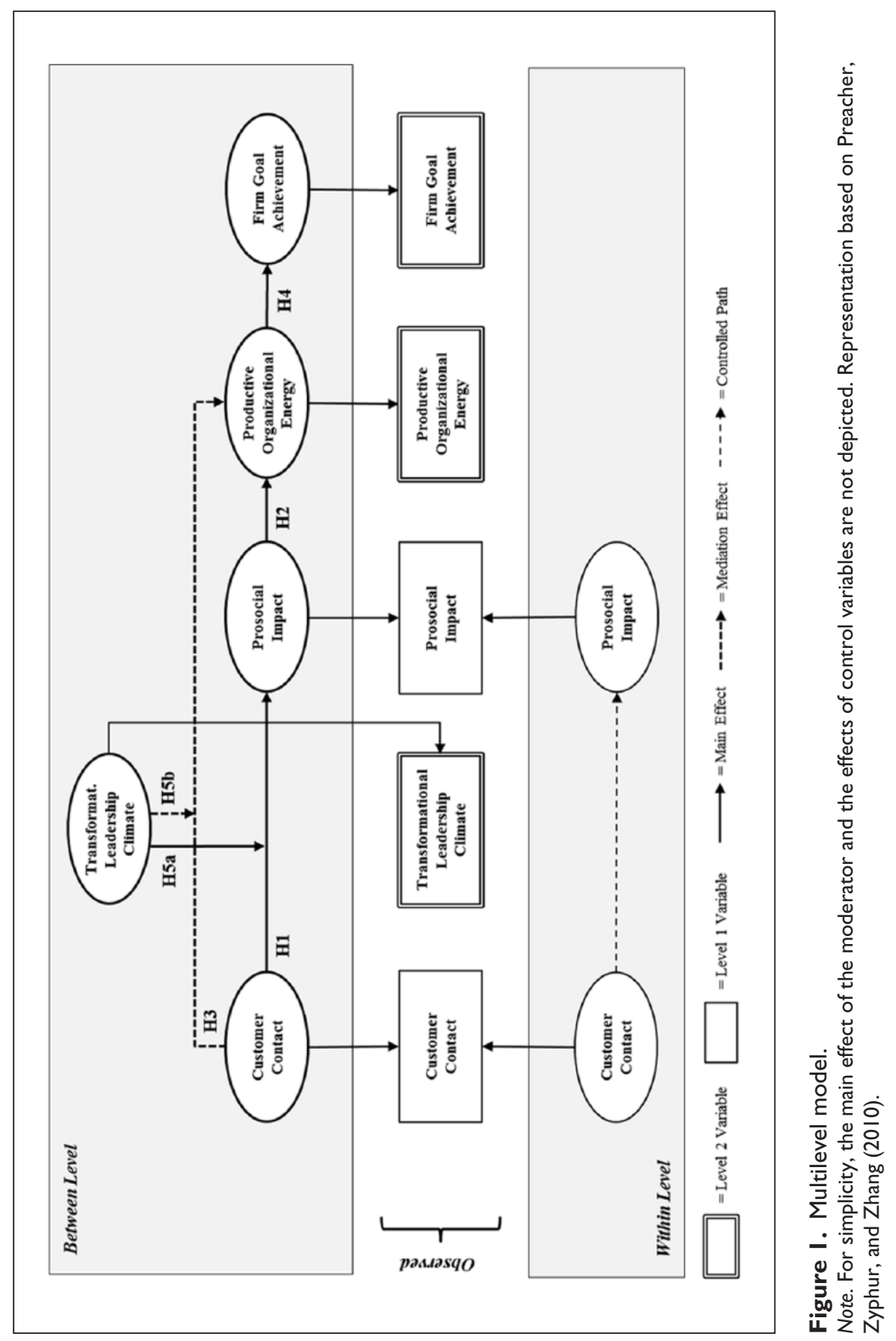


every business" (Drucker, 1973, p. 79), customers as a firm's external beneficiaries seem to be a highly relevant group of beneficiaries when it comes to the experience of prosocial impact at the firm level. Third, recent research has shown that prosocial motivation converges at the collective level due to shared helping norms because organizational members sense each other's desire for making a difference in others' lives (Hu \& Liden, 2014). Such emergence of collective prosocial motivation can also be expected at the organizational level.

We draw from the interpersonal and organizational sensemaking perspective (Maitlis, 2005; Wrzesniewski et al., 2003) to show why the linkage of customer contact and prosocial impact should also be present at the organizational level. Although perceiving the prosocial impact of one's work might always be a subjective experience analogous to experiencing meaningfulness at work (Pratt \& Ashforth, 2003), research on interpersonal and organizational sensemaking supports the idea that others play a key role in shaping the perception of one's meaning (Maitlis, 2005; Wrzesniewski et al., 2003). Accordingly, organizational members might influence each other in their perceptions of their work's prosocial impact. The experience of prosocial impact of an individual employee who has customer contact might positively stimulate the perception of prosocial impact by another employee without customer contact as they both share the same employer and, hence, basically serve the same customers. ${ }^{5}$ In case the overall level of customer contact within the organization is high, all employees across the organization might experience that their firm makes a difference in the lives of the organization's customers due to the described interpersonal sensemaking processes. Thus, we expect that organizations at which the level of customer contact is high might rate higher on perceived prosocial impact than organizations with a low level of customer contact. Consequently, we posit as follows:

Hypothesis 1: Organizations with high levels of customer contact show higher degrees of prosocial impact.

\section{Prosocial Impact and Productive Organizational Energy}

Furthermore, we suggest that a high degree of prosocial impact within the organization will be positively related to productive organizational energy. According to the job impact framework, the experience of making a difference through one's work increases employees' prosocial motivation because they recognize a connection between their behavior and outcomes in customers' lives (Grant, 2007). This experience sparks the desire and focuses their efforts to benefit customers through their work. Furthermore, the motivated 
social information processing perspective supports the idea that organizational members sense each other's desire for making a difference in others' lives (De Dreu, Nijstad, \& van Knippenberg, 2008). Based on this view, recent research has provided evidence that prosocial motivation converges at the team level because team members gradually generate a shared knowledge regarding the level to which concern for others' welfare, in our case for customers' welfare, guides the team behavior (J. Hu \& Liden, 2014). Over time, the team as a whole develops norms, that is, informal standards for acceptable behavior (Ehrhart \& Naumann, 2004), on prosocial motivation (J. Hu \& Liden, 2014). Combining these two literatures on relational job design and shared prosocial motivation, we theoretically argue that higher degrees of prosocial impact within the organization increase the shared prosocial motivation so that the affective, cognitive, and behavioral energy in organizations might be stimulated and enhanced.

Regarding affective energy in organizations, we expect that a high degree of prosocial impact within an organization increases the amount of shared positive emotions such as happiness, enthusiasm, or inspiration. Research has shown that engaging in the act of helping brings about feelings of joy and happiness (e.g., Williamson \& Clark, 1989), that the experience of prosocial impact increases positive affect after some incubation time (Sonnentag \& Grant, 2012), and that observing others' helping behavior and their prosocial impact elicits the feeling of elevation (Algoe \& Haidt, 2009). Accordingly, we believe that those organizations in which employees sense that their collective work outcomes make a positive difference in others' lives also very likely elicit feelings of inspiration, happiness, and enthusiasm. Once these positive emotions are experienced by some members of the organization, they might spread within the organization due to emotional contagion processes that link the affective states of organizational members (Barsade, 2002). Accordingly, we expect that a high degree of prosocial impact within an organization should enhance the positive affective energy in organizations.

Referring to cognitive energy in organizations, we propose that a high degree of prosocial impact within an organization might also enhance the cognitive dimension of productive organizational energy. Research has revealed that employees with high perceived prosocial impact worked to effectively use the available information to shape strategic decisions, set priorities, innovate, and solve problems (Moynihan, Pandey, \& Wright, 2012). Consequently, it seems that employees are more creative, more cognitively flexible, and more mentally alert when they know that their work serves others. Based on motivated social information processing (De Dreu et al., 2008), employees with shared prosocial motivation might also process information more deliberately for the sake of collective goals and welfare. Thus, a high 
degree of prosocial impact within an organization should mobilize the cognitive energy in organizations.

Moreover, concerning behavioral energy in organizations, we believe that employees are more motivated to expend effort when they recognize that their actions benefit others. In accordance with classic expectancy and planned behavior theories of motivation, employees are more likely to direct their efforts toward achieving an outcome when they are aware that their actions have the potential to bring about a personally valued outcome (Ajzen, 1991; Van Eerde \& Thierry, 1996; Vroom, 1964). As benefiting others is one of the most important values across cultures (Schwartz \& Bardi, 2001) and as shared prosocial motivation might positively influence the level of helping norms (Grant \& Patil, 2012), employees across the organization might work more and harder to achieve and maintain prosocial impact through their work. Hence, a high degree of prosocial impact within an organization might enhance the behavioral energy in organizations.

To sum up, organizational members' experience of making a positive difference in others' lives should increase their desire and expectation to benefit others through their work also in the future so that the overall level of prosocial motivation within the organization is rising. Such upward development should activate the collective affective, cognitive, and behavioral energy in organizations. Consequently, we hypothesize the following:

Hypothesis 2: Organizations with high degrees of prosocial impact show higher productive organizational energy.

\section{The Mediating Role of Prosocial Impact}

Hypothesis 1 predicts a positive relationship between the overall level of customer contact and prosocial impact, and Hypothesis 2 predicts a positive relationship between the overall level of prosocial impact and productive organizational energy. Together, these hypotheses specify a model in which the level of customer contact indirectly enhances productive organizational energy by contributing to the overall level of prosocial impact within the organization. We assume that in an organization with high levels of customer contact, organizational members receive more information, feedback, and reactions from customers, which raises the overall awareness that their work is (positively) affecting others. According to the job impact framework (Grant, 2007), contact and closeness to external customers, a key beneficiary of the organization, should spark the desire to benefit others through work. Even if the feedback from customers would be negative, we still assume that parts of the conveyed information received by organizational members entail 
the experience that the provided products or services matter to others, that is, customers, and that the organization exerts influence on customers' lives. Such palpable experience that organizational members' work matter for customers, that is, has an impact on them, might make the desire to have a positive impact and to make a positive difference more likely because individuals across cultures value benevolence (Schwartz \& Bardi, 2001) and are likely to experience distress if they have to harm others through their work (Molinsky $\&$ Margolis, 2005). Drawing from recent research on shared prosocial motivation and helping norms (Grant \& Patil, 2012; J. Hu \& Liden, 2014), we further argue that once the desire to benefit others through work has been stimulated among some organizational members, it might positively affect other organizational members and spark their desire to do good through their work. Such a process might increase the overall level of prosocial motivation and raise the level of helping norms within the organization and in particular with respect to helping customers through their work, which, in turn, unleashes the productive organizational energy. In accordance with this reasoning, we posit:

Hypothesis 3: The degree of prosocial impact within the organization mediates the relationship between the level of customer contact and productive organizational energy.

\section{Productive Organizational Energy and Firm Goal Achievement}

Furthermore, we propose that firms with high productive organizational energy outperform other firms. Prior meta-analytic and longitudinal studies have provided evidence that employees' aggregate work attitudes and working behavior influence organizations' bottom lines (e.g., Harter, Schmidt, \& Hayes, 2002). Furthermore, researchers have revealed that productive organizational energy is positively linked to employees' work outcomes in terms of increased job satisfaction and decreased turnover intentions (Raes et al., 2013), and that there is a positive linkage between the level of productive energy in a work unit and its internal effectiveness (Cole et al., 2012).

Starting from these findings, we expect that employees' work intensity and their additional exerted efforts in the pursuit of the firm's goals are higher in firms with a high level of productive organizational energy so that firm goal achievement should be positively influenced. Drawing from research on normative influences among peers at work (Stewart, Courtright, \& Barrick, 2012), we suppose that employees get positively stimulated by those employees whose productivity level exceeds their own level so that the overall level of 
in-use energy is increased. If organizational members show high levels of collective affective, cognitive, and behavioral energy, they might jointly strive to achieve the firm's declared goals and surpass the expectations directed at them. While doing so, it is very likely that such behavior improves firm goal achievement. In contrast, employees in firms with a low level of productive organizational energy are not very enthusiastic and excited about their jobs, are not mentally alert for the sake of the firm's fate, and do not go the extra mile. Consequently, such firms might achieve their goals to a lesser extent, and hence not be superior in terms of their overall performance. Accordingly, we posit the following hypothesis:

Hypothesis 4: Productive organizational energy is positively associated with firm goal achievement.

\section{The Moderating Role of Transformational Leadership Climate}

Finally, we expect that a transformational leadership climate shapes the influence of a firm's level of customer contact on its perceived level of prosocial impact and eventually productive organizational energy because a transformational leadership climate is likely to guide organizational sensemaking processes in favor of the firm's positive contribution to customers. Until now, research on the individual level has yielded mixed findings regarding the effects of customer contact on employees, so researchers have recommended inspecting the underlying contingencies (Grandey \& Diamond, 2010). As a high level of customer contact may also include unpleasant and strenuous interactions with customers, customer contact might not always lead to increased levels of prosocial impact and collective energy within the organization due to difficulties of distilling the prosocial impact in such cases (Grant, 2008). An organization's transformational leadership climate might be able to (re)direct employees' attention to the positive contribution of their work and to (re)connect the experiences of customer contact to the higher purpose of the organization (Maitlis, 2005; Molinsky \& Margolis, 2005; Salancik \& Pfeffer, 1978).

Two past research routes on the individual-level support the expected moderating effect of transformational leadership climate. First, there is a long history on the notion that transformational leadership might buffer negative effects of stress or increase the positive effects of support systems at the workplace (e.g., Bass, 1985; Gavin \& Hofmann, 2002; Syrek, Apostel, \& Antoni, 2013; Wang, Rode, Shi, Luo, \& Chen, 2013; Wang \& Walumbwa, 2007). Second, researchers have suggested that transformational leadership not only affects whether stressors are perceived as hindrances or challenges 
(LePine, LePine, \& Jackson, 2004; Piccolo \& Colquitt, 2006) but also increases the positive effects of challenge stressors (LePine, Zhang, Crawford, \& Rich, 2016; Zhang, LePine, Buckman, \& Wei, 2014).

An organization's transformational leadership climate reflects the shared perception of followers throughout the organization that their direct leaders engage in transformational leadership behaviors (Menges, Walter, Vogel, \& Bruch, 2011). Such behaviors refer to leaders who articulate a captivating vision for the future, act as charismatic role models, foster the acceptance of common goals, set high performance expectations, provide individualized support, and stimulate their followers intellectually (Bass, 1985; Podsakoff, MacKenzie, Moorman, \& Fetter, 1990). According to Maitlis's (2005) conceptualization of four forms of organizational sensemaking processes, an organization's transformational leadership climate might be described as guided organizational sensemaking (i.e., employees' sensemaking processes are highly controlled and highly animated by leaders' sensegiving). Consequently, a transformational leadership climate may enable followers to make their experience of customer contact - even the strenuous ones - more valuable, because it idealizes, controls, and animates employees' perceptions and understanding of information. A transformational leadership climate might thereby foster employees' sensitivity and awareness of their perception of benefiting others through their work so that the degree of perceived prosocial impact within the organization might increase. However, if the transformational leadership climate is low, employees might find it difficult to derive cognitive and motivational benefit from customer contact, particularly in cases of unpleasant contact - because they lack a shared vision and idealized goals, which would allow them to attach positive meaning to these contacts. In such cases, the level of perceived prosocial impact would not be increased by customer contact.

Hypothesis 5a: A transformational leadership climate strengthens the relationship between the level of customer contact and prosocial impact when it is high but limits the relationship when it is low.

Assuming that a transformational leadership climate moderates the association between the level of customer contact and prosocial impact, it is also likely that a transformational leadership climate will conditionally influence the strength of the indirect relationship between customer contact and productive organizational energy, thereby demonstrating a pattern of moderated mediation between the study variables. ${ }^{6}$ Consequently, we expect the following: 
Hypothesis 5b: A transformational leadership climate moderates the positive and indirect effect of customer contact on productive organizational energy (through prosocial impact). Specifically, prosocial impact mediates the relationship between customer contact and productive organizational energy when transformational leadership climate is high but not when it is low.

\section{Method}

\section{Data Collection and Sampling}

As part of a larger survey study, we gathered data from 86 German firms that operate in a range of industries. Each firm received a detailed benchmark report in return for their participation. As 11 firms failed to provide data on all focal variables of interest, the final data from 75 firms comprised the answers of 9,094 employees (on average, 121 different employees responded per firm). In addition, we used the HR director or a member of the top management team (TMT) of each company as a key informant. Of the 75 organizations, 33 firms operated in the service sector, 22 in the production sector, 10 in the trade sector, and 10 in the finance sector. The organizational size ranged from 24 to 2,500 employees, and the average size was 360.39 employees $(S D=494.35)$. On average, $51 \%$ of the participating employees were male, 39 years old, and were employed at their company for 10 years. The average employee response rate per firm was $67 \%$.

To reduce common source bias, we measured variables from four different groups of respondents (Podsakoff, MacKenzie, Lee, \& Podsakoff, 2003), using the following procedure. All members of the participating organizations received an email with an invitation to participate in the study with a link to the questionnaire. Upon entering the online questionnaire, employees were randomly distributed via an algorithm programmed in the questionnaire to separate employee questionnaires. Customer contact and prosocial impact were measured in a first questionnaire; productive organizational energy was measured in a second questionnaire; transformational leadership climate was measured in a third questionnaire; and firm goal achievement was measured in a questionnaire that was answered by the HR director or a member of the TMT. A fourth group of employees also assessed the level of centralization within the firm, and the HR director or a member of TMT provided information on general characteristics of the organization, such as the number of employees, the organization's affiliation to an industry, and the type of customer served (business-to-business [B2B] vs. business-to-consumer [B2C]). 
The data sources and measurement of the main variables are displayed in Appendix A.

\section{Measures}

In line with our theoretical development, all measures were aggregated to the organizational level. The additive composition model provides the theoretical foundation to explain the emergence of customer contact and prosocial impact on the organizational level (Chan, 1998). Additive composition models specify a straightforward relationship between constructs at different levels, such that the meaning of the higher level construct is a summation of the lower level units. Importantly, the additive composition model does not assume a shared perception on certain work features, such as the degree of customer contact, and hence, allows individual-level variance. As outlined in the theory section, we assumed that the level of customer contact and the level of perceived prosocial impact could vary between jobs and persons. Accordingly, we measured these two constructs from an individual's perspective.

Productive organizational energy is based on a referent-shift consensus model, which implies that organizational members' perspective on the collective energy converges at the organizational level and that the referent for this measurement is on the collective organizational level (Chan, 1998). This is in line with prior research on productive organizational energy (e.g., Cole et al., 2012; Walter \& Bruch, 2010). Also in line with previous research on transformational leadership at the collective level we relied on a direct consensus model for transformational leadership climate (e.g., Menges et al., 2011; P. Wang et al., 2013). The underlying assumption is that each follower can best describe the behavior of his or her direct leader while the assessment of leadership behavior across the organization by organizational members would be rather imprecise (Javidan \& Dastmalchian, 1993).

To empirically validate the data aggregation for all measures, we calculated intraclass correlation coefficients $\left(\mathrm{ICC}_{1}\right.$ and $\mathrm{ICC}_{2}$; Bliese, 2000) and the average deviation index as an interrater agreement ratio $\left(\mathrm{AD}_{M(J)}\right.$; Burke, Finkelstein, \& Dusig, 1999). For the $\mathrm{ICC}_{1}$, values that are based on a significant one-way ANOVA are generally acceptable. For the $\mathrm{ICC}_{2}$, values of more than .60 are usually considered sufficient (Bliese, 2000; Chen, Mathieu, \& Bliese, 2004; Kenny \& La Voie, 1985). The $\mathrm{AD}_{M(J)}$ has several advantages over the $r_{w g}$ interrater agreement index (James, Demaree, \& Wolf, 1984). First, no modeling of a random null response distribution is required; only an a priori specification of a null response range of interrater 
agreement is preconditioned. Second, estimates in the metric of the original scale are provided, which allow for a more direct conceptualization and assessment of interrater agreement (Burke et al., 1999). For cutoff criteria for the $\mathrm{AD}_{M(J)}$, we followed the $\mathrm{c} / 6$ rule (the number of response options for an item divided by 6) proposed by Burke and Dunlap (2002). Thus, the value should be below 0.71 for 5-point response scales and below 1.17 for 7-point response scales.

Customer contact. We assessed customer contact by the nine-item scale of Grant (2008) on beneficiary contact to capture contact depth, breadth, and frequency with three items each. We adopted the referent from "beneficiaries" to "external customers" according to the study's context. Employees indicated their opportunities for contact with customers on a 7-point response scale $(1=$ strongly disagree and $7=$ strongly agree $)$. The exploratory factor analysis yielded a one-factor solution, so we averaged all items to form the overall index of customer contact. We obtained support for aggregating customer contact to the organizational level, $\mathrm{ICC}_{1}=.19, F(74,1401)=5.66, p<$ $.01, \mathrm{ICC}_{2}=.82, \mathrm{AD}_{M(J)}=0.99$.

Prosocial impact. Prosocial impact was assessed by the three-item scale of Grant (2008) on a 7 -point response scale $(1=$ strongly disagree and $7=$ strongly agree). We obtained support for aggregating prosocial impact to the organizational level, $\mathrm{ICC}_{1}=.11, F(74,2158)=4.73, p<.01, \mathrm{ICC}_{2}=.79$, $\mathrm{AD}_{M(J)}=1.00$.

Productive organizational energy. Productive organizational energy was assessed by the 14-item scale of Cole and colleagues (2012). Productive organizational energy comprises an affective, a cognitive, and a behavioral dimension, so the items reflected this structure. Responses to the five items of the affective dimension were given on 5-point frequency scales $(1=$ never and 5 = extremely often/always). The other two dimensions, the cognitive (five items) and the behavioral (four items), were answered on a 5-point agreement continuum $(1=$ strongly disagree and $5=$ strongly agree $)$. To form the overall index of productive organizational energy, we averaged the three distinct dimensions as done in prior research (e.g., Walter \& Bruch, 2010). Aggregation statistics showed sufficient results and were in line with previous research on collective energy or collective engagement, $\mathrm{ICC}_{1}=.11, F(74$, $2233)=4.69, p<.01, \mathrm{AD}_{M(J)}=0.45 ; \mathrm{ICC}_{2}=.79$ (Barrick et al., 2015; Raes et al., 2013). 
Transformational leadership climate. We used the Transformational Leadership Behavior Inventory of N. P. Podsakoff et al. (1990) to assess the transformational leadership climate. The instrument comprises 22 items that capture the following six dimensions of transformational leadership: providing intellectual stimulation, articulating a vision, communicating high performance expectations, fostering the acceptance of common goals, acting as a role model, and providing individualized support. In line with previous research (Menges et al., 2011; Walter \& Bruch, 2010), we adopted a direct consensus model to capture the transformational leadership climate of an organization and asked employees how frequently their direct leaders exhibit transformational leadership behaviors on a 5-point frequency scale $(1=$ never and $5=$ extremely often/always $)$. As aggregation statistics showed sufficient results, $\mathrm{ICC}_{1}=.11, F(74,2115)=4.60, p<.01, \mathrm{ICC}_{2}=.78$, $\mathrm{AD}_{M(J)}=0.57$, individual-level transformational leadership ratings were averaged into a single organizational-level measure of transformational leadership climate.

Firm goal achievement. We asked the HR director or a member of TMT of each company to evaluate the degree of firm goal achievement in the last 6 months via the following question: "To what extent did your company achieve its most important goals?" $(1=$ very minimal to none and $7=$ to a very large degree), based on prior research (Van Dyck, Frese, Baer, \& Sonnentag, 2005). Where possible, secondary performance data were collected and correlated with the survey-based performance measure. We were able to collect data on EBIT (earnings before interest and taxes) in euros for the concurrent and following year of the data collection for 49 firms. We used the percentage change in EBIT between the 2 years rather than absolute levels to eliminate firm-specific differences such as industry affiliation and firm size, and to enable comparability of different firms. The objective information and the managerial assessment of firm goal achievement are highly correlated $(r=.58, p<.01)$, indicating that the managerial performance evaluations are valid.

Control variables. In addition to the aforementioned variables, we included several control variables in the analyses. First, we added organizational size as a control variable to the analyses, because organizational size may influence employee attitudes and behaviors (Talacchi, 1960). Organizational size was measured by asking the key informant for the total number of employees in the organizations (converted to full-time equivalents). We log transformed the number of employees to reduce skewness in the distribution of 
this measure as applied in prior research (e.g., Schminke, Cropanzano, \& Rupp, 2002) because the number of employees in an organization might increase logarithmically (Gooding \& Wagner, 1985). Second, we also controlled for a firm's affiliation with service versus nonservice industries, because a firm's affiliation to the service industry might influence the firm's overall level of customer contact (Katz \& Kahn, 1978; Knight et al., 2017). Participant organizations were assigned a dummy-coded variable $(0=$ nonservice industry and $1=$ service industry). Third, the type of customer (business vs. private) may potentially influence prosocial impact. Thus, we control for business versus private customers of the organizations $(0=\mathrm{B} 2 \mathrm{~B}$ and $1=\mathrm{B} 2 \mathrm{C}$ ). Fourth, we controlled for the level of centralization within an organization. Organizations with decentralized structures may be closer to customers; thus, employees might have more customer contact on average and perceive higher levels of prosocial impact. Centralization was captured by the validated index of hierarchy of authority asking employees about their perception of power distribution within the organization (Dewar, Whetten, \& Boje, 1980). We obtained support for aggregating this variable to the organizational level $\mathrm{ICC}_{1}=.10, F(74,2219)=4.30, p<.01, \mathrm{ICC}_{2}=$ $.77, \mathrm{AD}_{M(\mathcal{)}}=1.10$.

\section{Measurement Model}

We assessed the factor structures of the focal research variables by conducting a confirmatory factor analysis with maximum-likelihood estimation procedures with aggregate responses on the organizational level (e.g., Bentler \& Dudgeon, 1996). We used a partial disaggregation technique for second-order constructs (e.g., Williams \& O'Boyle, 2008) to keep the ratio between parameters and cases acceptable. Due to the well-established factor structure of transformational leadership climate and productive organizational energy, we relied on the use of items parcels for these two constructs (Marsh, Lüdtke, Nagengast, Morin, \& von Davier, 2013), as applied in previous research (e.g., Grant, 2012; Raes et al., 2013). Thus, we created the three dimensions of the productive organizational energy measure by averaging the items for their respective dimensions. We did the same for the six dimensions of transformational leadership climate. Hence, the hypothesized measurement comprised four latent constructs with 21 items in total (including nine parcels). However, items relating to the three facets in the first-order construct customer contact may share additional variance not captured by the overall scale due to the reference and similarities in item wording. Thus, we correlated the error terms of the respective items, resulting in freeing nine constraints that lower 
Table I. Means, Standard Deviations, and Correlations of Study Variables.

\begin{tabular}{|c|c|c|c|c|c|c|c|c|c|c|}
\hline Variables & M & $S D$ & I & 2 & 3 & 4 & 5 & 6 & 7 & 8 \\
\hline I. Customer contact & 4.86 & 1.00 & $(.95)$ & & & & & & & \\
\hline 2. Prosocial impact & 5.08 & 0.69 & .53 & $(.93)$ & & & & & & \\
\hline $\begin{array}{l}\text { 3. Transformational } \\
\text { leadership climate }\end{array}$ & 3.75 & 0.40 & .45 & .55 & $(.8 \mathrm{I})$ & & & & & \\
\hline $\begin{array}{l}\text { 4. Productive } \\
\text { organizational energy }\end{array}$ & 3.54 & 0.35 & .43 & .58 & .52 & $(.88)$ & & & & \\
\hline $\begin{array}{l}\text { 5. Firm goal } \\
\text { achievement }\end{array}$ & 5.95 & 0.93 & .13 & .06 & .17 & .25 & & & & \\
\hline $\begin{array}{l}\text { 6. Organizational size } \\
(\mathrm{log})\end{array}$ & 5.17 & 1.21 & -.25 & -.41 & -.45 & -.32 & -.03 & & & \\
\hline 7. Industry service & 0.44 & 0.50 & .25 & .40 & .26 & .22 & -.05 & -.12 & & \\
\hline 8. $\mathrm{B} 2 \mathrm{C}$ & 0.76 & 0.43 & -.33 & -.21 & -.09 & .04 & .00 & -.12 & -.01 & \\
\hline 9. Centralization & 3.51 & 0.68 & -.43 & -.39 & -.57 & -.43 & -.30 & .33 & -.33 & -.16 \\
\hline
\end{tabular}

Note. $N=75$. All constructs refer to the organizational level. All $r>.24$ are significant at $p<.05$; all $r>.32, p<.0$ I. Cronbach's alphas appear on the diagonal in parentheses. $\log =\log$ transformed. B2C = business-to-consumer.

the degrees of freedom (e.g., Cole, Ciesla, \& Steiger, 2007). As the multivariate normality assumption was not met (Mardia Statistics: skew $=230.44, p<$ .01 and kurtosis $=566.44, p<.01$ ), we used the robust Satorra-Bentler MLM estimator. Fit statistics of the four-factor solution are largely in line with the guidelines of $\mathrm{Hu}$ and Bentler $(1999), \chi^{2}(174)=344.20$, comparative fit index $(\mathrm{CFI})=.91$, standardized root mean square residual $(\mathrm{SRMR})=.08$. All factor loadings were statistically significant and ranged from .96 to .97 for prosocial impact, .86 to .97 for customer contact, .74 to .97 for productive organizational energy, and .53 to .97 for transformational leadership climate. Chisquare difference tests showed that all alternative nested models achieved a significantly poorer fit. Thus, we fail to disconfirm the expected model, suggesting that it is one plausible representation of the underlying structure of the data.

\section{Results}

\section{Descriptive Statistics}

Table 1 presents means, standard deviations, and correlations of all study variables. As expected, customer contact related positively to prosocial impact 
$(r=.53, p<.01)$, to productive organizational energy $(r=.43, p<.01)$, and to the service industry $(r=.25, p<.05)$, while it related negatively to organization size $(r=-.25, p<.05)$ and centralization $(r=-.43, p<.01)$. Prosocial impact related positively to productive organizational energy $(r=.58, p<$ $.01)$. Furthermore, productive organizational energy positively related to firm goal achievement $(r=.25, p<.05)$.

\section{Analytical Approach}

We used Mplus Version 7.2 and the guidelines of Preacher et al. (2010) for testing multilevel mediation to estimate a moderated mediation model. More specifically, we estimated our hypothesized model on the between level (i.e., organizational level) while controlling for the within-level (i.e., individual level) relationship between customer contact and prosocial impact. This methodological approach allows us to decompose the variance of Level 1 variables (i.e., customer contact and prosocial impact) into within and between components and thereby accounts for the fact that relationships might differ between the between and the within levels. Consequently, we avoid a conflation of the conditional indirect effect of customer contact on productive organizational energy. We estimated the multilevel model using a full maximum-likelihood estimator, report standardized coefficients, and follow the suggestion of Preacher et al. (2010) to report directional tests for indirect effects.

\section{Tests of Mediation}

Model 1 in Table 2 presents the results for the multilevel mediation model. Regarding Hypothesis 1, customer contact was positively associated with prosocial impact on the organizational level $(\beta=.27, p<.05)$, while controlling for the within level effect between customer contact and prosocial impact $(\beta=.34, p<.01)$. Furthermore, with respect to Hypothesis 2 , the relationship between prosocial impact and productive organizational energy was supported $(\beta=.42, p<.01)$. Regarding Hypothesis 4 , the results showed that productive organizational energy was positively related to firm goal achievement $(\beta=.27, p<.10) .{ }^{7}$ Moreover, customer contact was found to have an indirect positive effect $(\beta=.12, p<.05,95 \%$ confidence interval $[\mathrm{CI}]=[.03, .21])$ on productive organizational energy, as we hypothesized (Hypothesis 3). Thus, Hypotheses 1, 2, 3, and 4 cannot be rejected. As the direct effect from customer contact to productive organizational energy is not significant $(\beta=.16, p=.17)$, the present model is a full mediation model. 


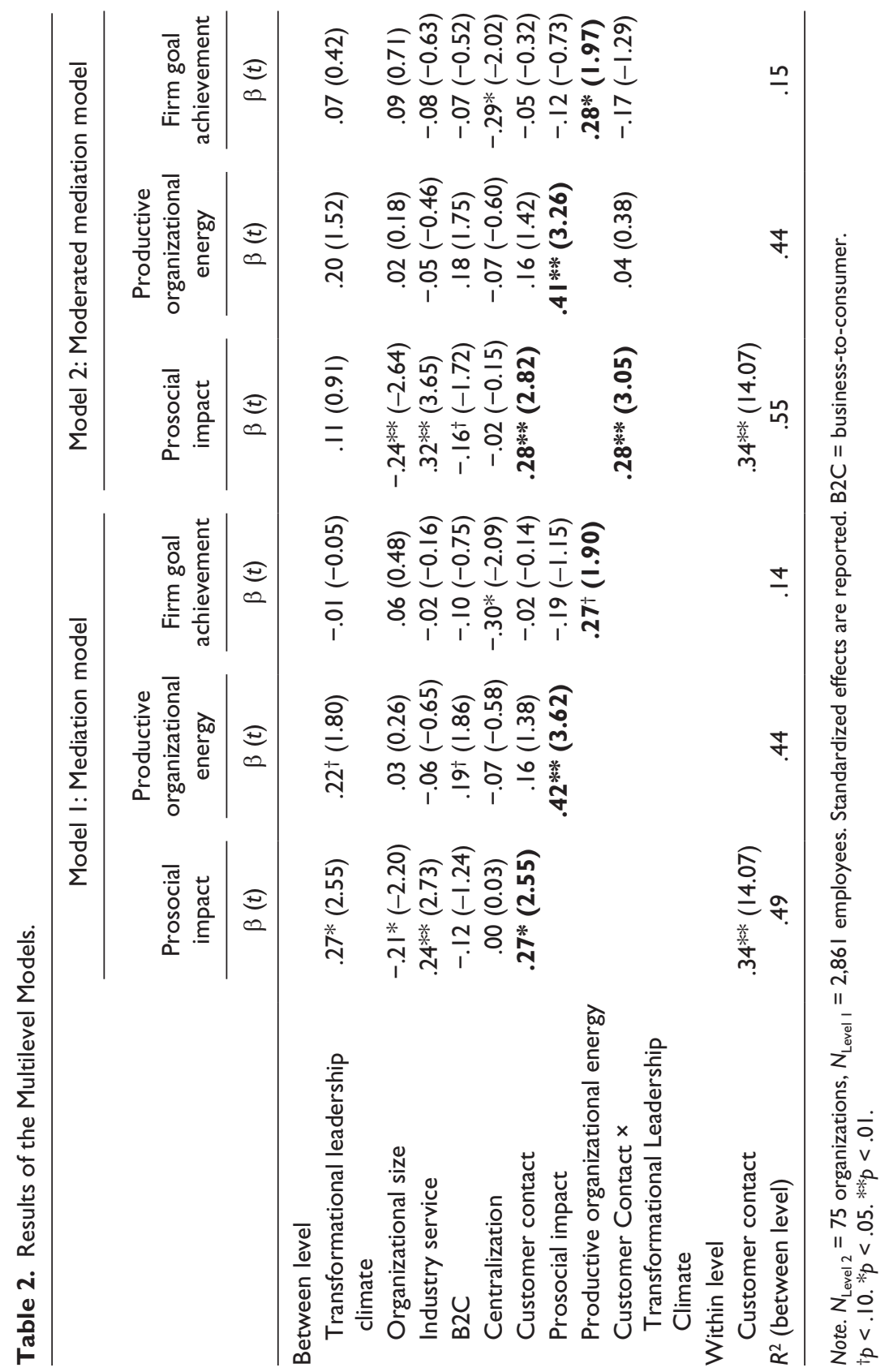




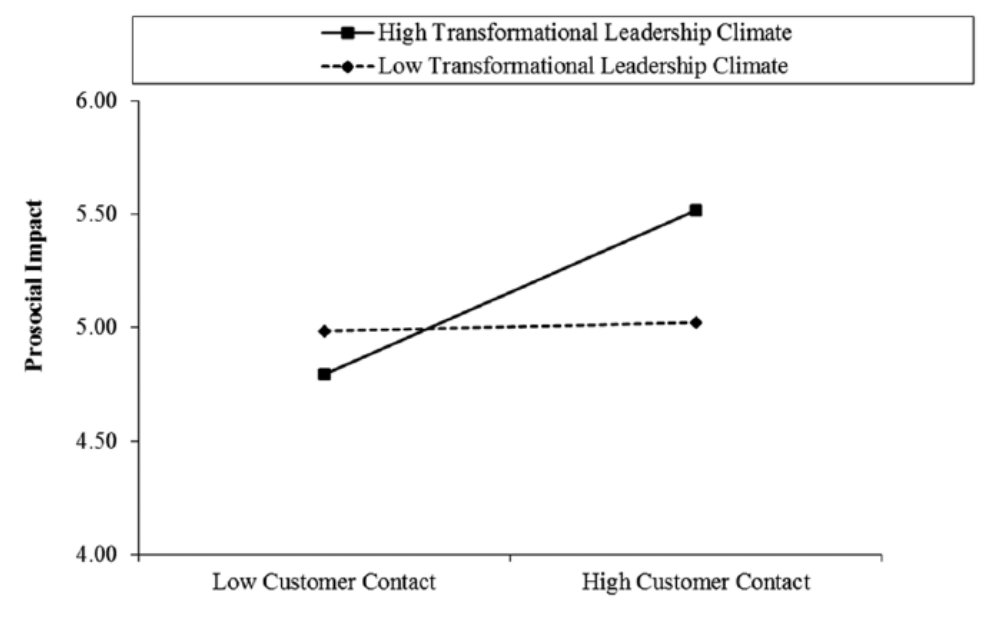

Figure 2. Interactive effect of customer contact and transformational leadership climate on prosocial impact.

Note. Low moderator variable refers to one standard deviation below the mean; high moderator variable refers to one standard deviation above the mean.

\section{Tests of Moderated Mediation}

Model 2 in Table 2 presents the results for the multilevel moderated mediation model. With regard to Hypothesis 5a, we predicted that the relationship between customer contact and prosocial impact would be reinforced for organizations with a high transformational leadership climate but limited for organizations with a low transformational leadership climate. Results indicated that the cross-product term of customer contact and transformational leadership climate on prosocial impact is significant $(\beta=.28, p<.01)$, thus Hypothesis 5 a cannot be rejected. We inspected the moderating effect of customer contact on prosocial impact at three values of transformational leadership climate: the mean (0), one standard deviation above the mean (1), and one standard deviation below the mean $(-1)$. The effect of customer contact on prosocial impact was positive and significantly different from zero at one standard deviation above the mean $(\beta=.56, p<.01)$ and at the mean $(\beta=.28$, $p<.01)$. At one standard deviation below the mean, the effect was not significant $(\beta=.00, p=.82)$. Figure 2 shows the graphical illustration of the moderating effect. 
To test the hypothesized moderated mediation model (Hypothesis 5b), we also examined the conditional indirect effect of customer contact on productive organizational energy (through prosocial impact) for the three common values of transformational leadership climate. The indirect effect was positive and significantly different from zero at one standard deviation above the mean $(\beta=.23, p<.01,95 \% \mathrm{CI}=[.10, .45])$ and at the mean $(\beta=.12, p<.05,95 \% \mathrm{CI}=[.03, .21])$ but not different from zero at one standard deviation below the mean $(\beta=.00, p=.42,95 \% \mathrm{CI}=[-.09, .09])$. Thus, Hypothesis $5 \mathrm{~b}$ cannot be rejected, indicating that a high transformational leadership climate reinforces the relationship between customer contact and productive organizational energy, while a low transformational leadership climate limits the relationship between customer contact and productive organizational energy.

For the sake of completeness, we tested the serial mediation of the conditional indirect effect starting from customer contact to firm goal achievement through prosocial impact and productive organizational energy. Despite its small effect size, this nonhypothesized indirect effect was positive and significantly different from zero with high transformational leadership climate $(\beta=.06, p<.10,90 \% \mathrm{CI}=[.02, .10])$ but not different from zero with low transformational leadership climate $(\beta=.00, p=.42,90 \%$ $\mathrm{CI}=[-.01, .01])$.

\section{Robustness Tests}

We conducted two additional analyses to test for the robustness of our results. First, very high levels of customer contact may potentially have deleterious effects on perceptions of prosocial impact and human energy (Grant \& Schwartz, 2011). Thus, we conducted a supplementary analysis on the potential curvilinear effects of customer contact on prosocial impact and productive organizational energy. In line with Knight and colleagues (2017), investigating the effects of organizational-level consumer-centric activity, we only found significant positive linear effects of customer contact. Including the curvilinear effects of customer contact into our model did not change our findings. Second, dispersion of customer contact due to the different types of jobs and roles within the organizations may potentially intervene with the mean level of customer contact. Thus, we conducted a further analysis controlling for dispersion of customer contact, captured by the standard deviation of employees' customer contact (Chan, 1998). We found that the dispersion of customer contact did not significantly affect prosocial impact, and all results remained stable. Both analyses are reported in Appendix B. 


\section{Discussion}

This study examined how and when a firm's level of customer contact influences productive organizational energy. We developed and empirically tested a model that proposed that high levels of customer contact activate the collective organizational energy because of employees' aggregate experience that their work matter. However, the experience of the prosocial impact of their work due to the firm's level of customer contact depends on a transformational leadership climate.

\section{Theoretical Implications}

The present study advances research on collective organizational energy and relational job design. We introduced a firm's level of customer contact as a novel factor that positively influences the collective human energy in organizations, which, in turn, improves firm goal achievement. While prior research on the collective energetic activation of organizational members focused on factors like management behavior or organizational structure (e.g., Raes et al., 2013; Walter \& Bruch, 2010), we extend this perspective by incorporating a firm's level of customer contact as an organizational characteristic for collective human energy in organizations. The integration of customers in theories about human energy in organizations is essential for the progress of knowledge about a sustainable model of collective human energy in organizations (Quinn et al., 2012). Furthermore, our work expands previous research on the organizational-level linkages of customer-centric activities and the firm's affective climate (Knight et al., 2017) by suggesting that not only the firm's industry affiliation but also the overall level of customer contact within a firm is positively linked to the level of (affective) organizational energy.

Importantly, our research untangled under which conditions customer contact is beneficial for organizations in terms of their energy. We found that a medium to high transformational leadership climate is an important condition for energizing the organization through customer contact. Transformational leadership across the organization might help to derive positive meaning from the firm's level of customer contact, which contributes to the experience of more prosocial impact within the organization, even when customer contact might require extra effort or unpleasant activities from organizational members. The finding that a transformational leadership climate shapes the influence of customer contact on the firm's level of human energy might also have implications for future multilevel research; it could be that the prior contradictory findings on the effects of customers on employees' motivation and 
well-being at the individual level (Grandey \& Diamond, 2010) might depend on the firm's leadership climate.

Our theoretical perspective and empirical examination also provided evidence that core elements of relational job design - customer contact and prosocial impact - operate in similar ways at higher levels beyond the individual level for which we control in our analyses, and beyond organizational design feature, such as centralization. For this purpose, we integrated research on relational job design on the individual level (Grant \& Parker, 2009) with recent advancements on shared prosocial motivation and tested our theoretical perspective empirically at the organizational level and beyond a centralized firm structure. As our results supported the proposed line of reasoning, our research adds to theoretical and empirical elaborations of job design at the collective level (Humphrey et al., 2007; Oldham \& Hackman, 2010) while incorporating insights from organizational design.

\section{Practical Implications}

The present investigation also has important implications for practice. First, we advise managers to increase a firm's overall level of customer contact to benefit from its positive effect on productive organizational energy through prosocial impact. To do so, we encourage strategic leaders and HR managers to systematically evaluate and optimize the level of a firm's customer contact. If possible, firms should enlarge those departments that provide good opportunities for organizational members to get in touch with customers. Furthermore, our findings further provide a striking argument why firms should not outsource their customer care center because such decision would quite certainly go along with a lower overall level of customer contact within a firm, which could diminish the productive organizational energy necessary to achieve a firm's goals.

Second, managers should integrate tasks with customer contact also in those job profiles that normally do not provide contact with customers, such as back-office jobs. However, as the firm's level of customer contact is not directly linked to productive organizational energy but mediated by the overall level of prosocial impact, practitioners should include contact with customers in a way that enables employees to vividly experience the prosocial impact of their work. Possible additional tasks for relationally enriched job profiles consists of doing some direct sales work, meeting customers at firm events, or conducting customer surveys.

Third, we strongly recommend building a high level of transformational leadership climate within the firm to enable the positive effects of customer contact on prosocial impact and productive organizational energy. If managers 
miss do to so, firms are not able to benefit from a higher level of customer contact. One promising way to enhance supervisors' transformational leadership behaviors across the organization is to offer professional training in transformational leadership behaviors to all supervisors (e.g., Barling, Weber, \& Kelloway, 1996). These trainings should of course explicitly address the energy-enhancing potential of customer contact and the crucial role of leaders to unleash it.

\section{Limitations and Future Research Directions}

As all empirical research, the present study has some limitations. A first restriction is that we were not able to apply experimental research methods, which makes it impossible to interpret the results as indicating causality. However, based on the theoretical arguments outlined before and the additional timelagged performance data for a subsample of the participating firms, the directions of causality in this study are likely. Future research might try to replicate the suggested causal relationships via experimental study designs. Second, although the sample was drawn from diverse industries, the sample is quite homogeneous in terms of cultural factors and organizational size, because all participant organizations were located in Germany and had less than 2,500 employees. The relationships found in this study might follow different patterns when measured in other countries or larger organizations. Consequently, researchers might investigate the suggested relationships in other contexts. Third, the measurement of firm goal achievement is a potential limitation of the present investigation, because we relied on subjective rather than objective ratings. However, in favor of our approach, we were able to validate our subjective measure with objective performance data for a subsample of firms.

Beyond addressing study limitations, prospective research might also consider the channel of the firms' customer contact. For example, due to the rapid increase of virtual work, scholars might explicitly take into account whether the contact between the firm and the customers is happening virtually or physically, because the energizing potential inherent in customer contact might be larger when experienced physically. In addition, prospective studies may investigate the influence of relational factors on collective human energy at work via constructs other than customer contact. Other stakeholder groups, such as suppliers or the society, or environmental changes might also exert influence on the collective organizational energy. Future research may want to consider these relational and contextual factors simultaneously, as they might activate the collective organizational energy in different ways and through different mechanisms. 


\section{Appendix A}

Data Sources and Measurement of Main Variables.

\begin{tabular}{|c|c|}
\hline Data source & Measure \\
\hline Employee & Customer contact (based on Grant, 2008) \\
\hline \multirow[t]{13}{*}{ Group I } & My job allows frequent communication with external customers. \\
\hline & $\begin{array}{l}\text { My job often gives me the opportunity to meet external } \\
\text { customers. }\end{array}$ \\
\hline & My job enables me to interact regularly with external customers. \\
\hline & $\begin{array}{l}\text { My job provides me with contact with different groups of external } \\
\text { customers. }\end{array}$ \\
\hline & My job allows me to interact with a variety of external customers. \\
\hline & My job enables me to meet diverse external customers. \\
\hline & $\begin{array}{l}\text { My job enables me to build close relationships with external } \\
\text { customers. }\end{array}$ \\
\hline & $\begin{array}{l}\text { My job allows me to form emotional connections with external } \\
\text { customers. }\end{array}$ \\
\hline & $\begin{array}{l}\text { My job gives me the chance to have meaningful communications } \\
\text { with external customers. }\end{array}$ \\
\hline & Prosocial impact (Grant, 2008) \\
\hline & $\begin{array}{l}\text { I feel that my work makes a positive difference in other people's } \\
\text { lives. }\end{array}$ \\
\hline & I am very aware of the ways in which my work is benefiting others. \\
\hline & $\begin{array}{l}\text { I am very conscious of the positive impact that my work has on } \\
\text { others. }\end{array}$ \\
\hline \multirow{17}{*}{$\begin{array}{l}\text { Employee } \\
\text { Group } 2\end{array}$} & Productive organizational energy (Cole, Bruch, \& Vogel, 20I2) \\
\hline & \\
\hline & Employees in our organization ... \\
\hline & ... feel excited in their job. \\
\hline & ... feel enthusiastic in their job. \\
\hline & ... feel energetic in their job. \\
\hline & ... feel inspired in their job. \\
\hline & ... feel ecstatic in their job. \\
\hline & $\ldots$ are ready to act at any given time. \\
\hline & $\ldots$ are mentally alert. \\
\hline & ... have a collective desire to make something happen. \\
\hline & ... really care about the fate of this company. \\
\hline & $\ldots$ are always on the lookout for new opportunities. \\
\hline & ... will go out of their way to ensure the company succeeds. \\
\hline & ... often work extremely long hours without complaining. \\
\hline & ... have been very active lately. \\
\hline & $\ldots$ are working at a very fast pace. \\
\hline
\end{tabular}




\section{Appendix A (continued)}

\begin{tabular}{|c|c|}
\hline Data source & Measure \\
\hline $\begin{array}{l}\text { Employee } \\
\text { Group } 3\end{array}$ & $\begin{array}{l}\text { Transformational leadership climate (N. P. Podsakoff, MacKenzie, } \\
\text { Moorman, \& Fetter, 1990) } \\
\text { My direct superior . . } \\
\ldots \text { provides me with new ways of looking at things. } \\
\ldots \text { forces me to rethink some of my own ideas. } \\
\ldots \text { stimulates me to think about old problems in new ways. } \\
\ldots \text { is always seeking new opportunities for the organization. } \\
\ldots \text { paints an interesting picture of the future for our company. } \\
\ldots \text { has a clear understanding of where we are going. } \\
\ldots \text { inspires others with his or her plans for the future. } \\
\ldots \text { is able to get others committed to his or her plans of the } \\
\ldots \text { future. } \\
\ldots \text { shows us that he or she expects a lot from us. } \\
\ldots \text { insists on only the best performance. } \\
\ldots \text { will not settle for second best. } \\
\ldots \text { fosters collaboration among work groups. } \\
\ldots \text { encourages employees to be "team players." } \\
\ldots \text { gets employees to work together for the same goal. } \\
\ldots \text { develops a team attitude and spirit among his or her } \\
\ldots \text { employees. } \\
\ldots \text { leads by role modeling. } \\
\ldots \text { provides a good model to follow. } \\
\ldots \text { leads by example. } \\
\ldots \text { acts without considering my feelings. } \\
\ldots \text { shows respect for my feelings. } \\
\ldots \text { behaves in a manner that is thoughtful of my personal needs. }\end{array}$ \\
\hline $\begin{array}{l}\text { Member of } \\
\text { HR/TMT }\end{array}$ & $\begin{array}{l}\text { Firm goal achievement (Van Dyck, Frese, Baer, \& Sonnentag, 2005) } \\
\text { To what extent did your company achieve its most important } \\
\text { goals? }\end{array}$ \\
\hline
\end{tabular}

Note. TMT = top management team. 


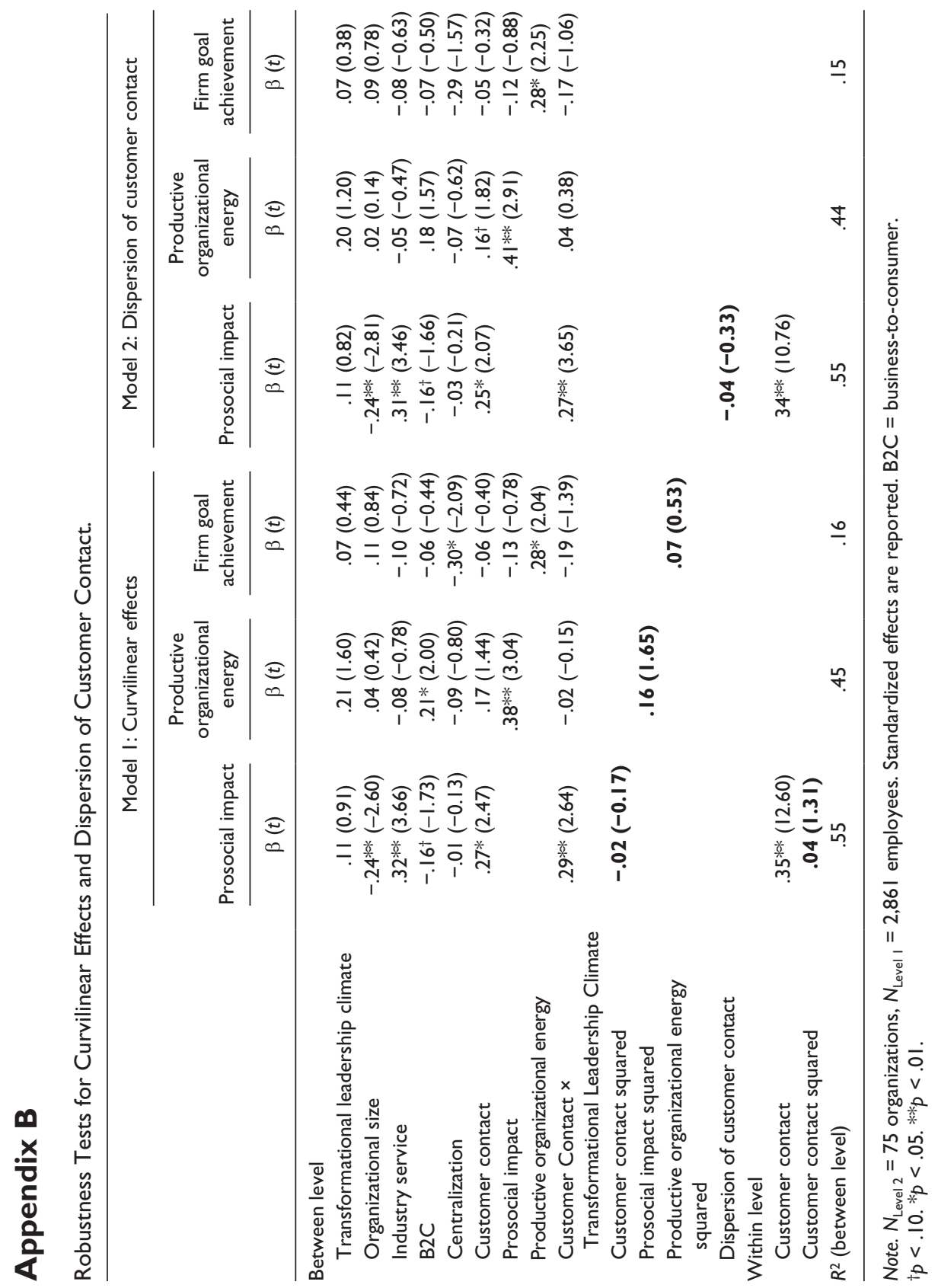




\section{Declaration of Conflicting Interests}

The author(s) declared no potential conflicts of interest with respect to the research, authorship, and/or publication of this article.

\section{Funding}

The author(s) received no financial support for the research, authorship, and/or publication of this article.

\section{Notes}

1. Affective organizational energy is similar to shared affect within groups because both constructs emphasize the experience of feeling the same certain emotions and moods within a group or an organization and the sharing of certain feelings among group or organizational members (Barsade \& Knight, 2015; Menges \& Kilduff, 2015; Parke \& Seo, 2017). However, affective energy as defined and operationalized by Cole, Bruch, and Vogel (2012) entails a clear indication of intensity and valence, that is, high intensity (e.g., enthusiasm) and only positive affect. While the phenomenon of shared affect within groups and subunits is similar to shared affect within organizations, the mechanisms for the convergence of affect within organizations overlap with the mechanisms at the group level to some extent but go beyond. At the organizational level, the theoretical underpinnings are more macro-level, such as attraction-selection-attrition processes, and, for instance, are based on the open systems perspective (cf. Knight, Menges, \& Bruch, 2017).

2. Cognitive organizational energy overlaps with some portions of shared cognition, which Cannon-Bowers and Salas (2001) described and classified as task-related knowledge and shared beliefs/attitudes. In detail, the work-related process knowledge on how to stay focused on the activities and get work done as well as shared beliefs/attitudes about the importance of focus are similar. Accordingly, shared cognitive energy within an organization describes a high level of mental persistence and a clear focus on the work activities that needs to be done, which leads to a high level of mental absorption among organizational members. However, it is different from transactive memory systems and other types of shared cognition because cognitive energy does not refer to task-specific knowledge, members' expertise, and mental representations of that expertise (Cannon-Bowers \& Salas, 2001; Lewis, 2003).

3. Although productive organizational energy shares some similarities with other constructs such as motivation and engagement, there are important differences between these constructs. Cole and colleagues (2012) provide a detailed discussion and an empirical examination of the discriminant validity of productive organizational energy and collective motivation. Importantly, they explicate that productive energy is a broader concept than motivation because it encompasses not only cognitive aspects (Locke \& Latham, 2004) but also affective and behavioral aspects. Hence, although an organization could be 
highly motivated, organizational members may lack positive feelings and agentic behavior so that the organization would not be productively energized. With respect to engagement, productive organizational energy and engagement have in common that both constructs entail an affective and a cognitive dimension. However, while collective organizational engagement serves as an "indicator of the overall motivational environment within the firm, and thus has a more descriptive focus" (emphasis as in the original, Barrick et al., 2015, p. 113), productive organizational energy, and particularly, the dimension of behavioral energy, captures the degree of the jointly invested efforts in terms of pace, intensity, and volume.

4. The focus on the firm's industry and the firm participation in consumer-centric activity was captured by the sum of percentages in the service and retail categories (and hence, excluding the other three categories, that is, wholesale trade, finance and insurance, and real estate). This approach assumes a zero interaction with customers and end consumers for the latter three categories, although at least some of the firm's employees within these latter industries are also very likely to have customer contact, while not all employees of a firm with the industry affiliation to service and retail might have a very high level of customer contact. Accordingly, to dissolve these generalizations yielding the potential of misleading conclusions, our research did not rely on a single informant of a firm to indicate the firm's industry affiliation and to derive the level of customer-centric activity for the entire organization based on the industry, but rather asked employees across jobs within the organization about their actual level of customer contact. An important advantage of the present approach refers to the manageability of the level of overall customer contact, for instance, through job design, while a change of an organization's affiliation to an industry is less or not mutable.

5. As we consider an organization as a system, in which the work of many individuals and teams is coordinated and orchestrated to form some type of holistic entity in terms of products and/or services, all work of organizational members is interdependent to some degree and basically serves the same customers. Moreover, we assume that some information of employees with high customer contact, such as facts and figures about market shares, feedback from customers, or customer engagement, might also be transferred, sent around within the organization, and hence, spill over among organizational members through means of virtual communication (even unidirectional), which does not per se require a bidirectional exchange between employees (Knight et al., 2017).

6. We do not expect that the transformational leadership climate also moderates the relationship between prosocial impact and productive energy because the influence of transformational leadership climate is based on organizational sensemaking processes guided by leaders. Once organizational members' view on the role and importance of customer contact has been adopted, and the overall perception of prosocial impact has been influenced, we do not expect a subsequent influence of transformational leadership climate on the relationship between prosocial impact and productive organizational energy. 
7. We replicated the productive organizational energy-firm goal achievement analysis using the objective performance measure as dependent variable for the subsample of 49 firms, using simple regression and the same controls as in the main analysis. Productive organizational energy was positively related to the percentage change in EBIT (earnings before interest and taxes; $\beta=.48, p<.01$ ).

\section{References}

Ajzen, I. (1991). The theory of planned behavior. Organizational Behavior and Human Decision Processes, 50, 179-211.

Algoe, S. B., \& Haidt, J. (2009). Witnessing excellence in action: The "other-praising" emotions of elevation, gratitude, and admiration. The Journal of Positive Psychology, 4, 105-127.

Atwater, L., \& Carmeli, A. (2009). Leader-member exchange, feelings of energy, and involvement in creative work. The Leadership Quarterly, 20, 264-275.

Bandura, A. (2001). Social cognitive theory: An agentic perspective. Annual Review of Psychology, 52(1), 1-26.

Barling, J., Weber, T., \& Kelloway, E. K. (1996). Effects of transformational leadership training on attitudinal and financial outcomes: A field experiment. Journal of Applied Psychology, 81, 827-832.

Barrick, M., Thurgood, G., Smith, T., \& Courtright, S. (2015). Collective organizational engagement: Linking motivational antecedents, strategic implementation, and firm level performance. Academy of Management Journal, 58, 111-135.

Barsade, S. G. (2002). The ripple effect: Emotional contagion and its influence on group behavior. Administrative Science Quarterly, 47, 644-675.

Barsade, S. G., \& Knight, A. P. (2015). Group affect. Annual Review of Organizational Psychology and Organizational Behavior, 2(1), 21-46.

Bass, B. M. (1985). Leadership and performance beyond expectations. New York, NY: The Free Press.

Bellé, N. (2014). Leading to make a difference: A field experiment on the performance effects of transformational leadership, perceived social impact, and public service motivation. Journal of Public Administration Research and Theory, 24, 109-136.

Bentler, P. M., \& Dudgeon, P. (1996). Covariance structure analysis: Statistical practice, theory, and directions. Annual Review of Psychology, 47, 563-592.

Bliese, P. D. (2000). Within-group agreement, non-independence, and reliability: Implications for data aggregation and analysis. In K. J. Klein \& S. W. J. Kozlowski (Eds.), Multilevel theory, research, and methods in organizations: Foundations, extensions, and new directions (pp. 349-381). San Francisco, CA: Jossey-Bass.

Bruch, H., \& Ghoshal, S. (2003). Unleashing organizational energy. MIT Sloan Management Review, 45, 45-51.

Bruch, H., \& Vogel, B. (2011). Fully charged: How great leaders boost their organization's energy and ignite high performance. Boston, MA: Harvard Business School Press. 
Burke, M. J., \& Dunlap, W. P. (2002). Estimating interrater agreement with the average deviation index: A user's guide. Organizational Research Methods, 5, 159-172.

Burke, M. J., Finkelstein, L. M., \& Dusig, M. S. (1999). On average deviation indices for estimating interrater agreement. Organizational Research Methods, 2, 49-68.

Cannon-Bowers, J. A., \& Salas, E. (2001). Reflections on shared cognition. Journal of Organizational Behavior, 22, 195-202.

Chan, D. (1998). Functional relations among constructs in the same content domain at different levels of analysis: A typology of composition models. Journal of Applied Psychology, 83, 234-246.

Chen, G., Mathieu, J. E., \& Bliese, P. D. (2004). A framework for conducting multilevel construct validation. In F. J. Yammarino \& F. Dansereau (Eds.), Research in multilevel issues: Multilevel issues in organizational behavior and processes (Vol. 3, pp. 273-303). Oxford, UK: Elsevier.

Christian, M. S., Eisenkraft, N., \& Kapadia, C. (2014). Dynamic associations among somatic complaints, human energy, and discretionary behaviors: Experiences with pain fluctuations at work. Administrative Science Quarterly, 60, 66-102.

Cole, D. A., Ciesla, J. A., \& Steiger, J. H. (2007). The insidious effects of failing to include design-driven correlated residuals in latent-variable covariance structure analysis. Psychological Methods, 12, 381-398.

Cole, M. S., Bruch, H., \& Vogel, B. (2012). Energy at work: A measurement validation and linkage to unit effectiveness. Journal of Organizational Behavior, 33, 445-467.

De Dreu, C. K. W., Nijstad, B. A., \& van Knippenberg, D. (2008). Motivated information processing in group judgment and decision making. Personality and Social Psychology Review, 12(1), 22-49.

Dewar, R. D., Whetten, D. A., \& Boje, D. (1980). An examination of the reliability and validity of the Aiken and Hage scales of centralization, formalization, and task routineness. Administrative Science Quarterly, 25, 120-128.

Drucker, P. F. (1973). Management. New York, NY: Harper \& Row.

Ehrhart, M. G., \& Naumann, S. E. (2004). Organizational citizenship behavior in work groups: A group norms approach. Journal of Applied Psychology, 89, 960-974.

Fritz, C., Lam, C. F., \& Spreitzer, G. M. (2011). It's the little things that matter: An examination of knowledge workers' energy management. Academy of Management Perspectives, 25(3), 28-39.

Gavin, M. B., \& Hofmann, D. A. (2002). Using hierarchical linear modeling to investigate the moderating influence of leadership climate. The Leadership Quarterly, 13(1), 15-33.

Gooding, R. Z., \& Wagner, J. A. (1985). A meta-analytic review of the relationship between size and performance: The productivity and efficiency of organizations and their subunits. Administrative Science Quarterly, 30, 462-481.

Grandey, A. A. (2000). Emotional regulation in the workplace: A new way to conceptualize emotional labor. Journal of Occupational Health Psychology, 5, 95-110.

Grandey, A. A., \& Diamond, J. A. (2010). Interactions with the public: Bridging job design and emotional labor perspectives. Journal of Organizational Behavior, $31,338-350$. 
Grandey, A. A., Kern, J. H., \& Frone, M. R. (2007). Verbal abuse from outsiders versus insiders: Comparing frequency, impact on emotional exhaustion, and the role of emotional labor. Journal of Occupational Health Psychology, 12, 63-79.

Grant, A. M. (2007). Relational job design and the motivation to make a prosocial difference. Academy of Management Review, 32, 393-417.

Grant, A. M. (2008). Designing jobs to do good: Dimensions and psychological consequences of prosocial job characteristics. The Journal of Positive Psychology, 3(1), 19-39.

Grant, A. M. (2012). Leading with meaning: Beneficiary contact, prosocial impact, and the performance effects of transformational leadership. Academy of Management Journal, 55, 458-476.

Grant, A. M., Campbell, E. M., Chen, G., Cottone, K., Lapedis, D., \& Lee, K. (2007). Impact and the art of motivation maintenance: The effects of contact with beneficiaries on persistence behavior. Organizational Behavior and Human Decision Processes, 103, 53-67.

Grant, A. M., \& Parker, S. K. (2009). Redesigning work design theories: The rise of relational and proactive perspectives. The Academy of Management Annals, 3, 317-275.

Grant, A. M., \& Patil, S. V. (2012). Challenging the norm of self-interest: Minority influence and transitions to helping norms in work units. Academy of Management Review, 37, 547-568.

Grant, A. M., \& Schwartz, B. (2011). Too much of a good thing: The challenge and opportunity of the inverted U. Perspectives on Psychological Science, 6, 61-76.

Harter, J. K., Schmidt, F. L., \& Hayes, T. L. (2002). Business-unit-level relationship between employee satisfaction, employee engagement, and business outcomes: A meta-analysis. Journal of Applied Psychology, 87, 268-279.

Hollensbe, E., Wookey, C., Hickey, L., \& George, G. (2014). Organizations with purpose. Academy of Management Journal, 57, 1227-1234.

$\mathrm{Hu}$, J., \& Liden, R. (2014). Making a difference in the teamwork: Linking team prosocial motivation to team processes and effectiveness. Academy of Management Journal, 58, 1102-1127.

Hu, L., \& Bentler, P. M. (1999). Cutoff criteria for fit indexes in covariance structure analysis: Conventional criteria versus new alternatives. Structural Equation Modeling, 6(1), 1-55.

Humphrey, S. E., Nahrgang, J. D., \& Morgeson, F. P. (2007). Integrating motivational, social, and contextual work design features: A meta-analytic summary and theoretical extension of the work design literature. Journal of Applied Psychology, 92, 1332-1356.

James, L. R., Demaree, R. G., \& Wolf, G. (1984). Estimating within-group interrater reliability with and without response bias. Journal of Applied Psychology, 69, $85-98$.

Javidan, M., \& Dastmalchian, A. (1993). Assessing senior executives: The impact of context on their roles. The Journal of Applied Behavioral Science, 29, 328-342. 
Katz, D., \& Kahn, R. L. (1978). The social psychology of organizations. New York, NY: John Wiley.

Kenny, D. A., \& La Voie, L. (1985). Separating individual and group effects. Journal of Personality and Social Psychology, 48, 339-348.

Knight, A., Menges, J., \& Bruch, H. (2017). Organizational affective tone: A meso perspective on the origins and effects of consistent affect in organizations. Academy of Management Journal, 61, 191-219. doi:10.5465/amj.2016.0671

Kozlowski, S. W. J., \& Klein, K. J. (2000). A multilevel approach to theory and research in organizations: Contextual, temporal, and emergent processes. In K. J. Klein \& S. W. J. Kozlowski (Eds.), Multilevel theory, research, and methods in organizations (pp. 3-90). San Francisco, CA: Jossey-Bass.

LePine, J. A., LePine, M. A., \& Jackson, C. L. (2004). Challenge and hindrance stress: Relationships with exhaustion, motivation to learn, and learning performance. Journal of Applied Psychology, 89, 883-891.

LePine, M. A., Zhang, Y., Crawford, E. R., \& Rich, B. L. (2016). Turning their pain to gain: Charismatic leader influence on follower stress appraisal and job performance. Academy of Management Journal, 59, 1036-1059.

Lewis, K. (2003). Measuring transactive memory systems in the field: Scale development and validation. Journal of Applied Psychology, 88, 587-603.

Lilius, J. (2012). Recovery at work: Understanding the restorative side of "depleting" client interactions. Academy of Management Review, 37, 569-588.

Locke, E. A., \& Latham, G. P. (2004). What should we do about motivation theory? Six recommendations for the twenty-first century. Academy of Management Review, 29, 388-403.

Lykken, D. T. (2005). Mental energy. Intelligence, 33, 331-335.

Maitlis, S. (2005). The social processes of organizational sensemaking. Academy of Management Journal, 48(1), 21-49.

Marsh, H. W., Lüdtke, O., Nagengast, B., Morin, A. J. S., \& von Davier, M. (2013). Why item parcels are (almost) never appropriate: Two wrongs do not make a right-Camouflaging misspecification with item parcels in CFA models. Psychological Methods, 18, 257-284.

McGrath, J. E., Arrow, H., \& Berdahl, J. L. (2000). The study of groups: Past, present, and future. Personality and Social Psychology Review, 4, 95-105.

Menges, J. I., \& Kilduff, M. (2015). Group emotions: Cutting the Gordian knots concerning terms, levels of analysis, and processes. The Academy of Management Annals, 9, 845-928.

Menges, J. I., Walter, F., Vogel, B., \& Bruch, H. (2011). Transformational leadership climate: Performance linkages, mechanisms, and boundary conditions at the organizational level. The Leadership Quarterly, 22, 893-909.

Molinsky, A., \& Margolis, J. (2005). Necessary evils and interpersonal sensitivity in organizations. Academy of Management Review, 30, 245-268.

Morgeson, F. P., \& Hofmann, D. A. (1999). The structure and function of collective constructs: Implications for multilevel research and theory development. Academy of Management Review, 24, 249-265. 
Moynihan, D. P., Pandey, S. K., \& Wright, B. E. (2012). Prosocial values and performance management theory: Linking perceived social impact and performance information use. Governance, 25, 463-483.

Oldham, G. R., \& Hackman, J. R. (2010). Not what it was and not what it will be: The future of job design research. Journal of Organizational Behavior, 31, 463-479.

Parke, M., \& Seo, M.-G. (2017). The role of affect climate in organizational effectiveness. Academy of Management Review, 42, 334-360.

Piccolo, R. F., \& Colquitt, J. A. (2006). Transformational leadership and job behaviors: The mediating role of core job characteristics. Academy of Management Journal, 49, 327-340.

Podsakoff, N. P., MacKenzie, S. B., Moorman, R. H., \& Fetter, R. (1990). Transformational leader behaviors and their effects on followers' trust in leader, satisfaction, and organizational citizenship behavior. The Leadership Quarterly, 1, 107-142.

Podsakoff, P. M., MacKenzie, S. B., Lee, J. Y., \& Podsakoff, N. P. (2003). Common method biases in behavioral research: A critical review of the literature and recommended remedies. Journal of Applied Psychology, 88, 873-903.

Podsakoff, P. M., MacKenzie, S. B., \& Podsakoff, N. P. (2016). Recommendations for creating better concept definitions in the organizational, behavioral, and social sciences. Organizational Research Methods, 19, 159-203.

Pratt, M. G., \& Ashforth, B. E. (2003). Fostering meaningfulness in working and at work. In K. S. Cameron, J. E. Dutton, \& R. E. Quinn (Eds.), Positive organizational scholarship: Foundations of a new discipline (pp. 309-327). San Francisco, CA: Berrett-Koehler Publishers.

Preacher, K. J., Zyphur, M. J., \& Zhang, Z. (2010). A general multilevel SEM framework for assessing multilevel mediation. Psychological Methods, 15, 209-233.

Quinn, R. W., \& Dutton, J. E. (2005). Coordination as energy-in-conversation. Academy of Management Review, 30(1), 36-57.

Quinn, R. W., Spreitzer, G. M., \& Lam, C. F. (2012). Building a sustainable model of human energy in organizations: Exploring the critical role of resources. The Academy of Management Annals, 6, 337-396.

Raes, A. M. L., Bruch, H., \& De Jong, S. B. (2013). How top management team behavioral integration can impact employee work outcomes: Theory development and first empirical tests. Human Relations, 66, 167-192.

Rousseau, D. M. (1985). Issues of levels in organizational research: Multi-level and cross-level perspectives. In B. M. Cummings \& B. M. Staw (Eds.), Research in organizational behavior (Vol. 7, pp. 1-37). Greenwich, CT: JAI Press.

Rupp, D. E., \& Spencer, S. (2006). When customers lash out: The effects of customer interactional injustice on emotional labor and the mediating role of discrete emotions. Journal of Applied Psychology, 91, 971-978.

Salancik, G. R., \& Pfeffer, J. (1978). A social information processing approach to job attitudes and task design. Administrative Science Quarterly, 23, 224-253. 
Schminke, M., Cropanzano, R., \& Rupp, D. E. (2002). Organization structure and fairness perceptions: The moderating effects of organizational level. Organizational Behavior and Human Decision Processes, 89, 881-905.

Schwartz, S. H., \& Bardi, A. (2001). Value hierarchies across cultures: Taking a similarities perspective. Journal of Cross-Cultural Psychology, 32, 268-290.

Sonnentag, S., \& Grant, A. M. (2012). Doing good at work feels good at home, but not right away: When and why perceived prosocial impact predicts positive affect. Personnel Psychology, 65, 495-530.

Spreitzer, G. M., \& Sonenshein, S. (2004). Toward the construct definition of positive deviance. American Behavioral Scientist, 47, 828-847.

Spreitzer, G. M., Sutcliffe, K., Dutton, J., Sonenshein, S., \& Grant, A. M. (2005). A socially embedded model of thriving at work. Organization Science, 16, 537-549.

Stewart, G. L., Courtright, S. H., \& Barrick, M. R. (2012). Peer-based control in self-managing teams: Linking rational and normative influence with individual and group performance. Journal of Applied Psychology, 97, 435-447.

Syrek, C. J., Apostel, E., \& Antoni, C. H. (2013). Stress in highly demanding IT jobs: Transformational leadership moderates the impact of time pressure on exhaustion and work-life balance. Journal of Occupational Health Psychology, 18, 252-261.

Talacchi, S. (1960). Organization size, individual attitudes and behavior: An empirical study. Administrative Science Quarterly, 398-420.

Van Dyck, C., Frese, M., Baer, M., \& Sonnentag, S. (2005). Organizational error management culture and its impact on performance: A two-study replication. Journal of Applied Psychology, 90, 1228-1240.

Van Eerde, W., \& Thierry, H. (1996). Vroom's expectancy models and work-related criteria: A meta-analysis. Journal of Applied Psychology, 81, 575-586.

Vroom, V. H. (1964). Work and motivation. New York, NY: Wiley.

Walter, F., \& Bruch, H. (2010). Structural impacts on the occurrence and effectiveness of transformational leadership: An empirical study at the organizational level of analysis. The Leadership Quarterly, 21, 765-782.

Wang, M., Liao, H., Zhan, Y., \& Shi, J. (2011). Daily customer mistreatment and employee sabotage against customers: Examining emotion and resource perspectives. Academy of Management Journal, 54, 312-334.

Wang, P., Rode, J. C., Shi, K., Luo, Z., \& Chen, W. (2013). A workgroup climate perspective on the relationships among transformational leadership, workgroup diversity, and employee creativity. Group \& Organization Management, 38, 334-360.

Wang, P., \& Walumbwa, F. O. (2007). Family-friendly programs, organizational commitment, and work withdrawal: The moderating role of transformational leadership. Personnel Psychology, 60, 397-427.

Williams, L. J., \& O’Boyle, E. H. (2008). Measurement models for linking latent variables and indicators: A review of human resource management research using parcels. Human Resource Management Review, 18, 233-242. 
Williamson, G. M., \& Clark, M. S. (1989). Providing help and desired relationship type as determinants of changes in moods and self-evaluations. Journal of Personality and Social Psychology, 56, 722-734.

Wrzesniewski, A. C., Dutton, J. E., \& Debebe, G. (2003). Interpersonal sensemaking and the meaning of work. Research in Organizational Behavior, 25, 93-135.

Zhang, Y., LePine, J. A., Buckman, B. R., \& Wei, F. (2014). It's not fair ... or is it? The role of justice and leadership in explaining work stressor-job performance relationships. Academy of Management Journal, 57, 675-697.

Associate Editor: Richard Orlando

Submitted Date: May 31, 2017

Revised Submission Date: May 4, 2018

Acceptance Date: May 21, 2018

\section{Author Biographies}

Petra Kipfelsberger is a postdoctoral research associate at the Institute for Leadership and Human Resource Management at the University of St. Gallen, Switzerland. Her research interests include human energy in organizations, the influences of customers on employees and on the organizational climate, and meaningfulness at work.

Heike Bruch is a professor of leadership and director of the Institute for Leadership and Human Resource Management at the University of St. Gallen, Switzerland. Her research interests include organizational energy, leaders' action, emotions in organizations, and healthy leadership.

Dennis Herhausen is an assistant professor of marketing and project leader at the Institute of Marketing at the University of St. Gallen, Switzerland. His research interests include customer relationships, marketing strategy implementation, digital marketing, and multilevel modeling. 